\title{
Urgences
}

\section{Les métamorphoses d'un différend}

\section{Danielle Saint-Cyr}

Numéro 13, mars 1986

Éclats d'atelier

URI : https://id.erudit.org/iderudit/025223ar

DOI : https://doi.org/10.7202/025223ar

Aller au sommaire du numéro

Éditeur(s)

Urgences

ISSN

0226-9554 (imprimé)

1927-3924 (numérique)

Découvrir la revue

Citer ce document

Saint-Cyr, D. (1986). Les métamorphoses d'un différend. Urgences, (13), 53-54.

https://doi.org/10.7202/025223ar

Ce document est protégé par la loi sur le droit d'auteur. L’utilisation des services d’Érudit (y compris la reproduction) est assujettie à sa politique d'utilisation que vous pouvez consulter en ligne.

https://apropos.erudit.org/fr/usagers/politique-dutilisation/
Cet article est diffusé et préservé par Érudit.

Érudit est un consortium interuniversitaire sans but lucratif composé de l’Université de Montréal, l’Université Laval et l’Université du Québec à Montréal. Il a pour mission la promotion et la valorisation de la recherche. https://www.erudit.org/fr/ 


\section{LES MÉTAMORPHOSES D'UN DIFFÉREND Danielle Saint-Cyr}

L'onde glisse. Lentement. Deux yeux maléfiques surgissent: d'abord estompés, puis légèrement embrouillés et finalement éclatants lorsque l'onde s'immobilise. Férandi ondule sous d'intermittents soubresauts. Une longue tignasse verdoyante frémit, de part et d'autre. Soudain, un tentacule s'en échappe. II serre, serre encore et encore jusqu'à l'étouffement.

Morvanvi suffoque. II sue. Vitantou déploie le parasol. Regrets. Les yeux se voilent peu à peu. L'ombre suit le mouvement d'ouverture de l'ombrelle. Deux billes noires regardent, se balançent, s'éteignent et tombent. Elles roulent à une vitesse incroyable, laissent une trace curviligne, profondément sculptée dans l'édredon de robes de tournesol qui masque les dalles crénelées. D'un geste vif, Vitantou les saisit. (Elle s'y prend de la même façon pour saisir les diptères importuns.) Elle s'assoit près de quelqu'un qui pourrait être Morvanvi. Ce dernier est "muré". Impossible de l'apercevoir. Une houppe de cheveux ambroisiaques, semblable à un funambule grimaçant, agrippé au crénelage de la muraille, trahit une présence. "Qui a érigé ce mur?" demande Vitantou. Seul le sujet de la sphère, où la houppe prend racine, le sait. Vitantou ignore qu'elle a participé, avec lui, au murage.

Le mur de la façade, celui sur lequel Vitantou est "collée", dépasse de deux pouces les trois autres qui ont six pieds. C'est Morvanvi qui le fait. Ce mur est presque entièrement dissimulé par des ronces et des lierres enchevêtrés. Vitantou, toujours "collée au mur", attend la détonation qui est passée outre et qui ne viendra pas. Le mur, donc, en sa hauteur, a six pieds et deux pouces. II n'émet aucun son et nul ne peut le dépasser. Vitantou, piquée de curiosité, s'agrippe aux lierres et grimpe. Ses chevilles sanguinolentes heurtent les ronces, mais qu'importe! Elle poursuit l'escalade. Une tête guivrée surgit à travers le feuillage. D'horribles trous noirs en guise d'yeux... Vitantou y pousse les deux billes d'ébène qu'elle serrait encore dans sa main gauche, lui offre 
une giroflée à cinq feuilles et la tête s'estompe prestement. La grimpeuse atteint bientôt le sommet qui a six pieds et deux pouces, on l'a déjà dit. Le quadrilatère irrégulier de deux pouces, pour les côtés est, ouest et nord, qu'elle devrait apercevoir d'en haut, n'y est pas. Morvanvi non plus. Les trois murs sont en effet disparus. Étaient-ils là en début d'escalade? Vitantou en doute à présent. II ne devait y avoir qu'un seul mur... qui n'était pas là non plus lorsque Morvanvi arriva.

L'objectif de Vitantou culbute et elle dévale au pied du mur. Elle s'est "cognée" la tête. Sa vue s'embrouille. Elle croit apercevoir Morvanvi là, tout près. Le mur a disparu. Morvanvi prononce quelques mots. Férandi reparaît. Un bras entoure Vitantou, la serre et elle suffoque. La sueur perle sur son front. Morvanvi déploie le parasol. Les yeux de Vitantou s'éteignent brusquement. Deux billes noires tombent et roulent sur les dalles. Morvanvi les attrape et les regarde rouler dans sa main gauche. Puis, il marche lentement vers la rivière, ouvre la main gauche et libère les petites sphères qui, illico, atteignent le fond. Morvanvi rebrousse chemin et "rase" un mur qu'il ne voit pas. Pourtant, une houppe... mais, nous l'avons dit, il ne voit pas le mur, ni la houppe et s'en va. 